\title{
Distribuição de investimentos públicos, infraestrutura urbana e desigualdade socioespacial em Curitiba
}

\author{
Public investments distribution, urban infrastructure and socio-spatial \\ inequality in Curitiba
}

Tainá Andreoli Bittencourt[a] (D), José Ricardo Vargas de Faria[b] (D)

\author{
[a] Universidade de São Paulo (USP), Centro de Estudos da Metrópole (CEM), Escola Politécnica (POLI), São \\ Paulo, SP, Brasil \\ [b] Universidade Federal do Paraná (UFPR), Centro de Estudos em Planejamento e Políticas Urbanas (CEPPUR), \\ Departamento de Transportes, Curitiba, PR, Brasil
}

Como citar: Bittencourt, T. A., \& Faria, J. R. V. (2021). Distribuição de investimentos públicos, infraestrutura urbana e desigualdade socioespacial em Curitiba. urbe. Revista Brasileira de Gestão Urbana, 13, e20190300. https://doi.org/10.1590/2175-3369.013.e20190300

\section{Resumo}

Este artigo tem como objeto a distribuição espacial de recursos públicos em infraestrutura urbana e sua relação com a dinâmica imobiliária e as desigualdades socioespaciais, tomando como caso de estudo a cidade de Curitiba. Inicialmente, o espaço intraurbano foi mapeado conforme níveis de precariedade segundo as condições dos domicílios, serviços públicos urbanos, infraestrutura, renda e oferta de transporte público. Em seguida, foi analisada a distribuição espacial dos investimentos realizados pelo poder público municipal em obras públicas entre 2005 e 2016, mais especificamente em pavimentação, edificações, iluminação pública, pontes e drenagem. Por fim, a partir da introdução de elementos referentes à atuação imobiliária, procurou-se confrontar a configuração das intervenções públicas urbanas com o comportamento do mercado imobiliário e com as demandas sociais. Ficou evidenciado que as precariedades também se manifestam na repartição diferencial de recursos em obras públicas que, ao invés de contribuir efetivamente para a justiça social, reforçam a distribuição desigual dos benefícios e ônus da urbanização.

Palavras-chave: Investimentos públicos. Desigualdade socioespacial. Políticas urbanas.

\begin{abstract}
This paper addresses the spatial distribution of public investments in urban infrastructure and its relationship with the real estate dynamics and socio-spatial inequalities, taking Curitiba as a case study. Initially, we mapped the intra-urban space according to the levels of household precariousness, urban public services, infrastructure, income, and public transport provision. Then, we analyze the spatial distribution of the investments made by the municipal government between 2005 and 2016 in public works such as paving, buildings, public lighting, bridges, and drainage. Finally, from the analysis of recent real estate dynamics, we sought to confront the configuration of public interventions in the urban space with the behavior of the real estate market and social demands. It became evident that urban
\end{abstract}

TAB é engenheira civil, doutoranda em Engenharia de Transportes, e-mail: taina.bittencourt@usp.br

JRVF é engenheiro civil, doutor em Planejamento Urbano e Regional, e-mail: jrvfaria@ufpr.br 
precariousness also manifests itself in the differential allocation of resources in public works that, instead of effectively contributing to social justice, reinforces the unequal distribution of the benefits and burdens of urbanization.

Keywords: Public investments. Socio-spatial inequalities. Urban policies.

\section{Introdução}

O Direito à Cidade não se resume à justa distribuição dos benefícios e responsabilidades decorrentes do processo de urbanização ou à "[...] liberdade individual de acesso a recursos urbanos" (Harvey, 2014, p. 74), mas ao direito coletivo de produzir outra cidade (Harvey, 2014; Lefebvre, 2011). No entanto, não é sem causa que o tema da desigualdade no acesso aos serviços e à infraestrutura urbana é uma dimensão destacada nas preocupações de planejadores, pesquisadores, gestores e militantes urbanos. Reflexões sobre justiça urbana e sua relação com o planejamento e as políticas públicas têm longa trajetória no pensamento sobre as cidades no Brasil (Kowarick, 1979; Maricato, 1979) e no mundo (Cohen, 2020), mas não perderam atualidade.

Nesse contexto, em diferentes perspectivas, a ação do poder público emerge como um instrumento protagonista na reprodução ou redução da desigualdade social e então na construção de um projeto de desenvolvimento (Furtado, 1944; Piketty, 2014), inclusive no âmbito do espaço (Maricato, 2013a). As políticas públicas urbanas, seja por meio da atuação direta sobre o território e sobre o ambiente construído, seja por meio de políticas organizadas espacialmente, podem alterar as condições locais e o acesso da população residente em diferentes áreas da cidade a bens e serviços, reduzindo os impactos da desigualdade de renda (Verbist et al., 2012).

Contudo, sendo a cidade e o Estado campos de contínuas disputas entre atores sociais com interesses distintos pelo território, além da incidência do poder público e das experiências e modificações do espaço pelos seus habitantes, as ações da iniciativa privada também se tornam decisivas no processo de transformação urbana (Harvey, 2014). Isso porque, para estes capitais cujos processos de acumulação estão diretamente vinculados à produção da cidade, tais como o mercado imobiliário, de terras ou de serviços inerentemente urbanos, as características da estrutura e das políticas urbanas definem grande parte da sua lucratividade, acirrando as disputas sobre o seu controle (Marques, 2016).

E, se os conflitos pelos recursos coletivos e pelo direito de transformar a cidade são comuns aos contextos urbanos, não raro são negados e reduzidos no discurso político e social. Ressalta-se o caráter ideológico do planejamento e da política urbana, capazes de produzir um discurso simultâneo de afirmação e omissão de determinados aspectos e lugares da cidade (Vainer, 2012). Em Curitiba, grande exemplo desse fenômeno, o discurso do planejamento modelo, reproduzido localmente e internacionalmente, opõe-se às heterogeneidades e desigualdades socioespaciais, com realidades e vivências distintas sobre o espaço (Garcia, 1997; Oliveira, 2000). Desta forma, o presente artigo inserese no campo de análise de políticas públicas urbanas e busca estudar a atuação dos governos municipais recentes na implementação e manutenção da infraestrutura urbana, direcionada ora às necessidades da população, ora aos investimentos privados, relacionados aos legados históricos do urbanismo local. Para tanto, tem como foco a cidade de Curitiba, visto o seu legado concreto e simbólico quanto às intervenções urbanísticas.

0 estudo é estruturado em três seções principais. Primeiramente, são problematizadas as relações entre poder público, políticas urbanas e infraestrutura na construção e reconstrução da cidade, designando usos e ocupações desiguais do espaço e dos elementos urbanos. Em seguida, toma-se como estudo a cidade de Curitiba, discutindo os aspectos metodológicos e contextuais que guiam a presente análise. Por fim, partindo de um diagnóstico espacial das condições de precariedade, analisa a distribuição dos recursos destinados à infraestrutura urbana pela prefeitura no período recente e 
confronta tais intervenções com o comportamento imobiliário, avançando na discussão da ação concreta do poder público sobre o território e suas populações.

\section{Urbanização, políticas públicas e infraestrutura}

0 processo de urbanização tem sido amplamente relacionado ao sistema econômico mundial. A partir da integração e proximidade entre unidades produtivas, centros de troca e de consumo, a construção da cidade permite a concentração de elementos que estruturam relações de produção e reprodução social (Castells, 2009; Lojkine, 1997). Para além do espaço de aglomeração, a própria terra e os elementos urbanos são colocados como mecanismos de absorção do produto excedente e, portanto, como parte do processo de acumulação de capital (Harvey, 2006; Vainer, 2012). A economia política da cidade e da urbanização (Santos, 2012; Singer, 2010) também coloca o problema da divisão social e espacial do trabalho, das distintas ações e apropriações de classes e grupos sociais no território (Harvey, 2014).

No capitalismo periférico, as relações de exploração e precarização do trabalho se intensificam e se aprofundam na construção desigual do espaço urbano, analisada por diversos autores com recortes na desigualdade de acesso à habitação e serviços (Maricato, 1979, 2013a), na periferização e territorialização da pobreza (Bonduki \& Rolnik, 1979; Roy \& Crane, 2015), na espoliação urbana e ausência ou precariedade de infraestrutura (Kowarick, 1979, 2000) e na segregação residencial (Caldeira, 2000; Villaça, 1998). Mais recentemente, destacam-se os impactos dos mercados globais e financeiros nas desigualdades e políticas locais, em que a disputa por investimentos internacionais pauta e constrange as decisões dos poderes públicos e privados nas cidades (Fix, 2007; Rolnik, 2015).

0 problema da territorialização da desigualdade, portanto, é complexo e, em essência, relacional. Como se depreende das análises referenciadas, a distribuição da pobreza (Roy \& Crane, 2015) e dos serviços e infraestruturas urbanas (Jordan \& Livert, 2016), por exemplo, não devem ser compreendidos apenas como questões de localização, mas como parte da produção social do espaço urbano que decorre da "ação de agentes sociais concretos" (Corrêa, 2014) em contextos históricos e condições socioespaciais dadas. Essa dimensão política da urbanização requer a análise do Estado, compreendido como condensação material de relações de poder (Poulantzas, 1980; Jessop, 2016), e dos conteúdos de sua "produção" (programas, ações e decisões políticas), ou, em outras palavras, do que se convencionou definir como políticas públicas (Souza, 2006). Essa produção assume formas específicas quanto aos grupos mobilizados, ao processo de formulação e implementação das políticas públicas, bem como às instituições e contextos na qual está inserida (Marques, 2016). Assim, a inseparabilidade entre Estado, políticas públicas e território (Steinberger, 2013) é considerada neste trabalho como categoria fundamental para compreensão dos processos de urbanização centralmente permeados por políticas nacionais e locais (Maloutas, 2008).

Cohen (2020), analisando o desenvolvimento histórico dos conteúdos relacionados ao conceito de política urbana em países em desenvolvimento, demonstra o progressivo incremento de tal noção. Partindo, no início do século 20, de uma perspectiva essencialmente administrativa (ou federativa), a política urbana incorpora preocupações com as questões habitacionais e de infraestrutura na década de 1960 e ambientais e de provisão de serviços em contexto de desigualdade a partir da década de 1990. Apesar de ser orientado por uma perspectiva positiva da ação de Estado, o autor reconhece que no "mundo real" a aplicação de algumas políticas urbanas nacionais em contextos locais frequentemente são "antipobres" e não fortalecem as capacidades gestão das funções urbanas no nível municipal (Cohen, 2020).

Esse aparente desvio se explica pelo caráter contraditório do Estado. Ao tempo em que a atuação estatal - e, em especial as políticas públicas urbanas de infraestrutura, como destacam Lojkine (1997) e Castells (2009) - ocorre por meio de investimentos produtivos necessários à acumulação e à reprodução da força de trabalho, e investimentos sociais necessários à legitimação e estabilização do 
sistema capitalista (Poulantzas, 1980), as relações político-econômicas são ainda mediadas por regras e práticas formais, operacionais e informais construídas historicamente que constrangem as ações do Estado (Hall \& Taylor, 1996).

Nesse sentido, dada a correlação entre poder político e poder aquisitivo, grupos (e áreas) de alta renda tenderiam a receber proporcionalmente mais benefícios líquidos das ações do Estado (Karabarbounis, 2011), influenciando a formação dos preços no mercado de solo urbano, reforçando o perfil de ocupação (Vetter et al., 1981) e inclusive aumentando as desigualdades de renda a longo prazo (Chatterjee \& Turnovsky, 2012).

Contudo, outros elementos relativizam as ações estatais, constituindo instrumentos para as classes populares ampliarem suas condições de vida e de seus lugares na cidade. Dentre eles, destacam-se a mobilização social de grupos de baixa renda na reivindicação de direitos e na imposição de demandas frente ao Estado (Sader, 1988), bem como o papel das eleições democráticas e do vínculo eleitoral dos governantes, que oferecem benefícios pontuais a determinadas áreas, em especial nos períodos que antecedem momentos eleitorais (Kuschnir, 2000; Povitkina \& Bolkvadze, 2019). Inclusive, a configuração espacial de investimentos públicos dialoga com o poder de legislação e regulamentação estatal que, ao separar cidade formal e informal, legitima a falta de políticas em regiões periféricas e estimula negociações em paralelo à ordem oficial, constituindo bases para relações personalistas (Rolnik, 1997).

A relação entre investimentos, recursos econômicos e representação política não é direta, e poucos estudos empíricos conseguiram demonstrar os diferentes mecanismos que influenciam os investimentos estatais com recorte espacial, em especial no período recente. Na análise do perfil da ação do Estado por meio de investimentos públicos no Rio de Janeiro e em São Paulo, foram verificados investimentos precoces nas periferias e uma consonância maior entre distribuição de recursos e perfil político-ideológico do Executivo do que entre ciclos eleitorais (Marques, 2000; Marques \& Bichir, 2001). Ao contrário, em Florianópolis, investimentos históricos em infraestrutura viária consolidaram eixos nobres da cidade e contribuíram para a conurbação de locais de elite, aumentando sua segregação (Sugai, 2002). Em nível nacional, em Moçambique, províncias que apresentavam os níveis mais baixos de acesso a infraestruturas básicas registraram os menores níveis de investimento em infraestrutura, não acompanhando o crescimento populacional (Mahdi et al., 2019).

Ainda, para além da implementação da infraestrutura necessária à provisão de serviços públicos, que constituem o foco da maioria destas análises e que afetam diretamente a sua quantidade e disponibilidade, a distribuição espacial de políticas também envolve características qualitativas e institucionais relacionadas à continuidade da atenção pública, alterando as condições locais de acesso (Pires, 2019; Torres et al., 2006).

Destarte, a intervenção do poder público na conformação do espaço urbano não implica necessariamente em resultados esperados ou no atendimento dos objetivos propostos pelo planejamento. Tal grau de discordância deriva, entre outros fatores, da disputa ideológica e prática no âmbito das políticas urbanas, pela ação política e econômica dos segmentos interessados, bem como da apropriação desigual dos seus ônus e benefícios. Aprofundar o conhecimento sobre esses processos, no entanto, não pode prescindir de uma investigação sobre a distribuição espacial dos investimentos, a relação das intervenções urbanas com os processos sociais de produção ou de reprodução (valor de troca e valor de uso) e, consequentemente, as relações de poder entre classes e grupos sociais que coabitam o espaço urbano. Em outras palavras, demandam uma investigação à luz de uma economia política da produção do espaço. A contribuição específica deste trabalho reside em explorar a relação entre distribuição de investimentos públicos em infraestrutura urbana e a desigualdade socioespacial, tomando como objeto de estudo a cidade de Curitiba, cujo histórico de planejamento e política urbana oferece caminhos relevantes para a análise atual. 


\section{Curitiba como objeto de estudo}

Curitiba é composta por 75 bairros que abrangem um território de $435 \mathrm{~km}^{2}$ e populados por cerca de 1,7 milhão de pessoas, segundo o último censo demográfico (IBGE, 2010). Eixos de transporte estruturam o espaço urbano central, exemplificando a tríade do planejamento urbano local: integração entre transporte coletivo, sistema viário e uso e ocupação do solo (Figura 1).

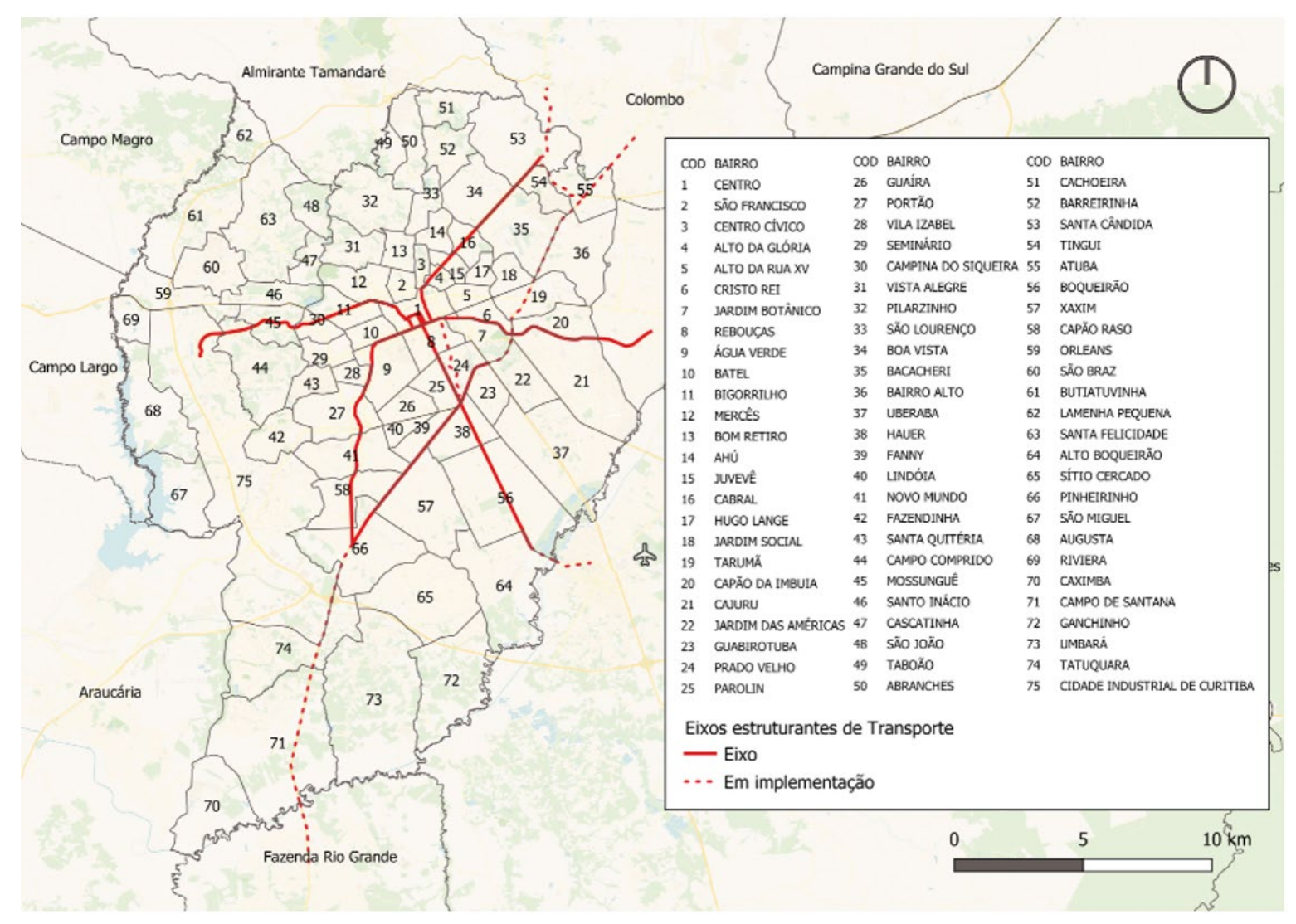

Figura 1 - Bairros de Curitiba. Fonte: os Autores (2019).

Seguindo o padrão de urbanização e reestruturação econômica nos países periféricos, Curitiba desenvolveu-se com um caráter intensamente acelerado e concentrado, no que tange aos aspectos socioespaciais, refletindo-se na periferização da pobreza (Moura, 2009) e na oposição e segregação entre grupos (Firkowski \& Moura, 2014). No entanto, a cidade destaca-se no universo do planejamento urbano e de transportes, sendo frequentemente tomada como referência para a elaboração de projetos e planos em cidades do Brasil e do mundo.

$\mathrm{O}$ contraste entre realidade urbana e imagem de cidade-modelo do city-marketing curitibano evidencia a produção de modelos urbanos que sustentam concepções parciais da cidade, oferecendo obstáculos à compreensão das desigualdades presentes no território e, especialmente, do papel do poder público nesses processos. Destaca-se o planejamento urbano racional e tecnicista desde as décadas de 1960/70, relacionado à consolidação dos interesses das classes proprietárias e à divisão desigual do espaço (Souza, 2001). Tal aliança, também materializada no contexto institucional e político-partidário, permitiu a conformação de uma tradição em planejamento praticado por grandes nomes em urbanismo e que serviu de base para um projeto político dominante (Oliveira, 2000). Nesse sentido, verifica-se a existência de um modelo Curitiba de aparente sucesso amplamente difundido e exportado e que, de alguma forma, é utilizado como legitimação à apropriação desigual dos espaços da cidade (Garcia, 1997). 
A crítica à cidade modelo, que emergiu na literatura do planejamento urbano em Curitiba no final da década de 1990, tem orientado diversas pesquisas nas últimas duas décadas. A constituição de fronteiras de desigualdade na produção das "novas periferias" metropolitanas (Polli, 2006), a ausência da questão habitacional que conforma um discurso lacunar de planejamento (Albuquerque, 2007), os impactos das políticas urbanas na valorização imobiliária e no acesso aos serviços públicos (Borges, 2009), a produção do espaço e os mecanismos de apropriação e produção de vantagens locacionais por meio da articulação entre Estado e capital imobiliário (Pilotto, 2010), a dinâmica de produção dos espaços informais de moradia (Silva, 2012) e as políticas de obscurecimento do preço da terra (Bertol, 2013) são fenômenos que ilustram a significativa produção teórica sobre as contradições da produção da cidade de Curitiba.

Portanto, se a história de Curitiba foi marcada pela continuidade partidária e ideológica no executivo municipal e na produção da cidade, questiona-se a permanência dessa continuidade em gestões recentes, bem como seus legados e impactos na política urbana contemporânea, isto é, a extensão da reprodução ou ruptura com as antigas práticas políticas e urbanísticas. Assim sendo, Curitiba é um objeto interessante para a análise da atuação do Estado sobre o território em contraposição às desigualdades urbanas e à atuação dos atores sociais, em especial dos agentes privados imobiliários.

\section{Aspectos metodológicos}

A primeira categoria de análise é a desigualdade socioespacial quanto à infraestrutura. Indicadores de domicílios, serviços públicos de consumo coletivo, infraestrutura urbana e transporte público são avaliados por uma clusterização hierárquica, de modo a definir uma condição de precariedade que sintetize as características de cada espaço da cidade ${ }^{1}$.

A partir dos dados do censo demográfico (IBGE, 2010) e da URBS (2017), que opera o transporte público local, e então da mensuração das distâncias entre os clusters (por dendrogramas), foram definidos cinco níveis de precariedade: da mais alta (1) à mais baixa (5). Este processo foi realizado tendo como base os 75 bairros de Curitiba e também os 2.365 setores censitários da cidade, de forma a demonstrar as heterogeneidades em diferentes escalas.

A distribuição de recursos públicos em infraestrutura é avaliada pelos custos e especificações das obras municipais em infraestrutura, obtidos a partir dos relatórios de obras da Secretaria Municipal de Obras Públicas (Curitiba, 2016a). O recorte temporal da análise consiste no período entre 2005 e 2016, que abrange doze anos e três gestões municipais - Beto Richa (20052010, PSDB); Luciano Ducci (2010-2012, PSB); Gustavo Fruet (2013-2016, PDT) -, limitado pela disponibilidade de dados de obras e execuções orçamentárias em infraestrutura urbana junto à prefeitura.

Para a análise da distribuição de recursos privados são utilizadas informações dos certificados de vistoria de conclusão de obras da Secretaria Municipal de Urbanismo (SMU) e dos preços da terra urbana (terrenos) e dos lançamentos imobiliários (residenciais e comerciais), de domínio do Instituto Paranaense de Pesquisa e Desenvolvimento do Mercado Imobiliário e Condominial (INPESPAR) e do Sindicato da Indústria da Construção Civil no Estado do Paraná (SINDUSCON-PR).

A correção de todos os valores monetários para junho de 2018 tem como base o Índice Geral de Preços, calculado pela Fundação Getúlio Vargas.

\footnotetext{
${ }^{1}$ Foram avaliados dezessete indicadores referentes às cinco dimensões: domicílios precários, com mais de seis moradores e com canalização interna; abrangência da rede dos serviços de saneamento básico (água e esgoto), energia elétrica e coleta de lixo; sistema viário com iluminação pública, pavimentação, calçada, drenagem urbana e arborização; rendimento médio mensal per capita e fração de domicílios com renda per capita inferior a um salário mínimo; e oferta de linhas, pontos de parada e frequência dos ônibus.
} 


\section{A desigualdade socioespacial em Curitiba}

Tendo em vista a necessidade de compatibilização com os dados de investimentos públicos e privados, a análise que segue utiliza como unidade espacial os bairros, subdivisões do município que apontam realidades distintas no polo metropolitano. Contudo, a desigualdade estrutura-se e manifesta-se em diversos níveis, dimensões e escalas. Conforme mostrado na Figura 2 , são verificadas heterogeneidades internas aos bairros e que, apesar de manter o padrão centro e periferia que estrutura as cidades brasileiras, constituem um espaço intraurbano diverso, inclusive com níveis de precariedade importantes em regiões nobres e centrais, conforme já discutido em trabalho anterior (Bittencourt, 2019).

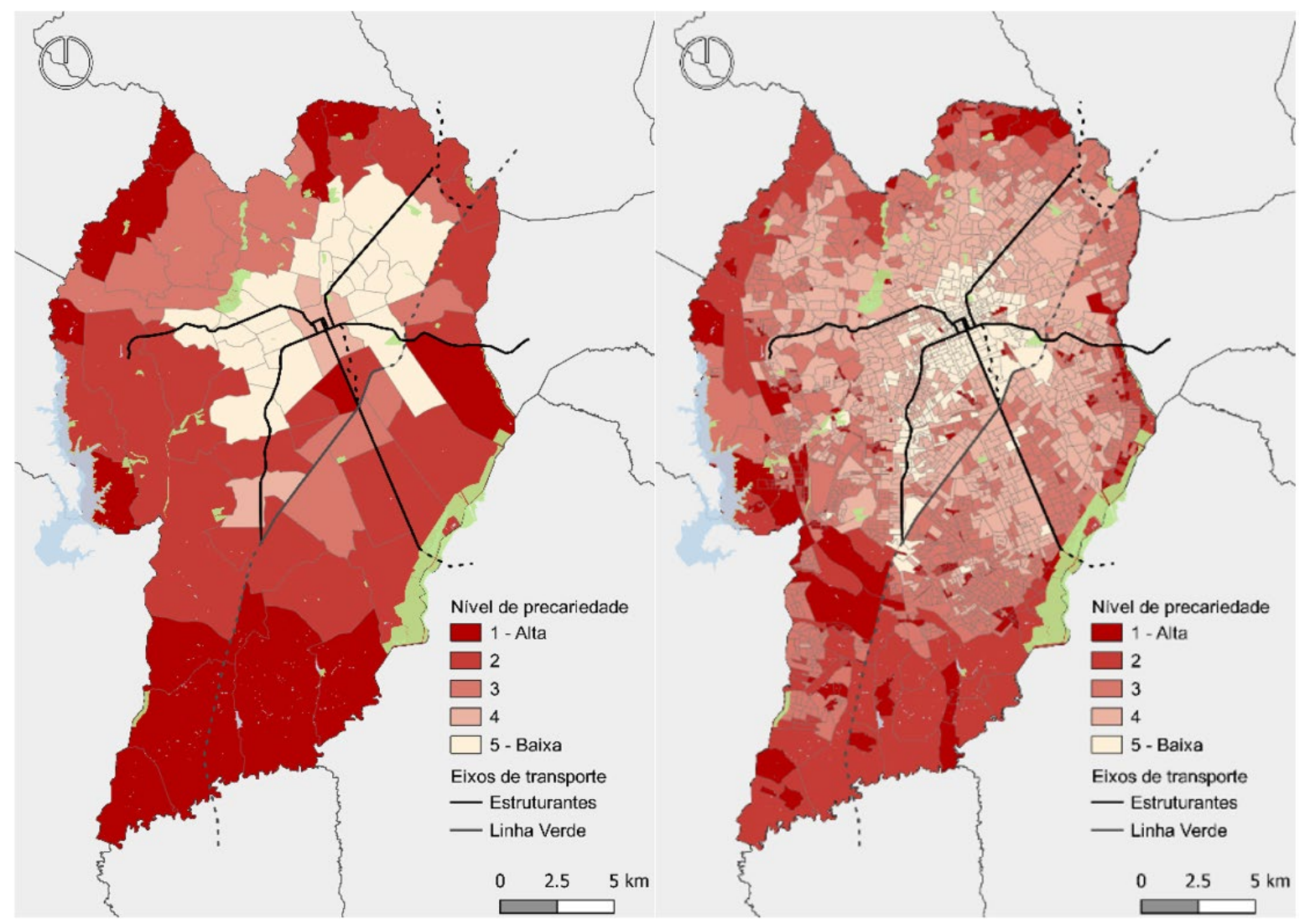

Figura 2 - Condições de precariedade no espaço intraurbano de Curitiba, por bairro (à esquerda) e por setor censitário (à direita). Fonte: Autores (2019), com dados do IBGE (2010) e URBS (2017).

Entre os locais mais precários da cidade, situados no grupo 1, estão treze bairros da periferia intraurbana, com precariedade crítica principalmente quanto à infraestrutura e renda. Aliás, o principal fator de união é justamente a falta de elementos característicos da urbanização, como pavimentação, calçadas e drenagem urbana. Nesta condição, está $28 \%$ da população curitibana. À condição de alta precariedade, somam-se outros dezenove bairros inseridos no grupo 2, com $28 \%$ da população. Apesar das melhores condições de acesso a serviços inerentemente urbanos, possuem alta precariedade quanto à renda e ao acesso ao transporte público.

Quinze bairros e 14\% da população compõem o grupo 3, que se apresenta como transição entre a região precária periférica e o polo central. Estão localizados na região noroeste da cidade ou no novo eixo estruturante da cidade, a Linha Verde, na direção nordeste/sudoeste. Verifica-se, contudo, uma descontinuidade ao sul da região central, na interseção entre eixos estruturantes de transporte. Estes locais são marcados por fortes desigualdades internas, com muitas habitações precárias de elevada 
densidade domiciliar. Apesar disso, estão mais próximos ao centro e, portanto, dispõem de maior acessibilidade, se comparados aos demais bairros do mesmo grupo.

A menor renda e o mais alto acesso ao transporte público fazem com que o núcleo central de Curitiba não corresponda à região de menor precariedade. Nas demais dimensões, as características observadas no grupo 4, que agrega quatro bairros e $4 \%$ da população, aproximam-se daquelas observadas no grupo 5, de menor precariedade. Composto pelo maior número de bairros (vinte e quatro ao todo) onde residem $25 \%$ da população curitibana, o grupo 5 apresenta características sólidas na maioria dos indicadores, com maior diferenciação no acesso ao transporte público coletivo. Entretanto, são estes os bairros com as maiores taxas de motorização individual ${ }^{2}$, o que revela uma menor dependência dos moradores em relação ao serviço público.

É importante destacar o papel central desempenhado pelos eixos estruturantes de transporte na conformação do território, visível na análise agregada por bairros e evidenciada pela análise na escala dos setores censitários. As áreas com melhores condições quanto às condições de moradia, renda e infraestrutura urbana tendem a acompanhar tais eixos, o que também se reflete no maior preço da terra urbana nestas regiões, conforme será discutido posteriormente. Se as linhas prioritárias de adensamento e desenvolvimento foram definidas, já no Plano Preliminar de Urbanismo de 1966, em grande parte com base nas áreas de residência das camadas de alta renda (Souza, 2001), os incentivos construtivos da regulação de uso e ocupação do solo e o legado histórico de investimentos em consonância com a estruturação do sistema viário e do transporte coletivo nestas regiões contribuíram para as atuais condições de infraestrutura e elitização, em especial nas áreas centrais.

Tendo em vista o atual contexto e a materialização do processo histórico de construção da cidade, a próxima seção busca compreender como investimentos públicos recentes em infraestrutura consolidam ou reduzem as desigualdades espaciais evidenciadas.

\section{Distribuição dos recursos públicos em infraestrutura urbana}

Na Prefeitura Municipal de Curitiba, os recursos destinados à infraestrutura urbana são administrados pela Secretaria Municipal de Obras Públicas (SMOP), que movimenta em média 620 milhões de reais anuais, o correspondente a pouco menos de $10 \%$ do total das despesas municipais ${ }^{3}$.

Para o período de janeiro de 2005 a dezembro de 2016, foram analisadas 5.192 obras, que somam mais de $\mathrm{R} \$ 2$ bilhões em valores corrigidos. 0 departamento de pavimentação reúne o maior número de obras e recursos, correspondendo a $64,7 \%$ do valor total executado pela SMOP no período. Este é então seguido pelo departamento de edificações $(26,5 \%)$, pelo departamento de iluminação pública (5,3\%) e pelo departamento de pontes e drenagem $(3,5 \%)$.

De maneira geral, conforme ilustrado na Figura 3, os maiores investimentos referem-se às obras da Linha Verde, novo eixo estruturante da cidade, e às outras obras viárias executadas no contexto da preparação da cidade para a Copa do Mundo de Futebol de 2014. Por isso, destacam-se os bairros ao longo deste eixo e na região leste da cidade, em direção ao aeroporto.

Contudo, se alguns bairros (como Hauer e Prado Velho), desconsiderando estas obras centrais para o período, ainda continuariam entre aqueles com mais altos recebimentos, outros (como Jardim das Américas e Fanny) passariam a compor a lista dos bairros com os menores recebimentos. Isso fortalece a hipótese de que grandes obras de infraestrutura representam mudanças importantes na estrutura urbana e na forma de planejar e intervir na cidade, servindo a objetivos específicos e alterando futuramente as dinâmicas locais (Oliveira et al., 2012).

\footnotetext{
2 Segundo dados da prefeitura, em 2016, a maioria absoluta dos bairros do grupo 5 apresenta taxas de motorização maiores do que a média da cidade, igual a 1,33 hab/veíc.

${ }^{3}$ Com base nas Despesas Orçamentárias Anuais entre 2005 e 2016 disponíveis no Sistema de Informações Contábeis e Fiscais do Setor Público Brasileiro (FINBRA-SICONFI).
} 
Já o Jardim Botânico aparece como local privilegiado de recursos em termos absolutos e relativos. Tal fato deve-se, além da concentração de intervenções de alto custo unitário, a exemplo do Viaduto Estaiado, da readequação da Rodoferroviária e da ampliação do Mercado Municipal, também à continuidade de investimentos ano a ano, com poucos pontos de queda.

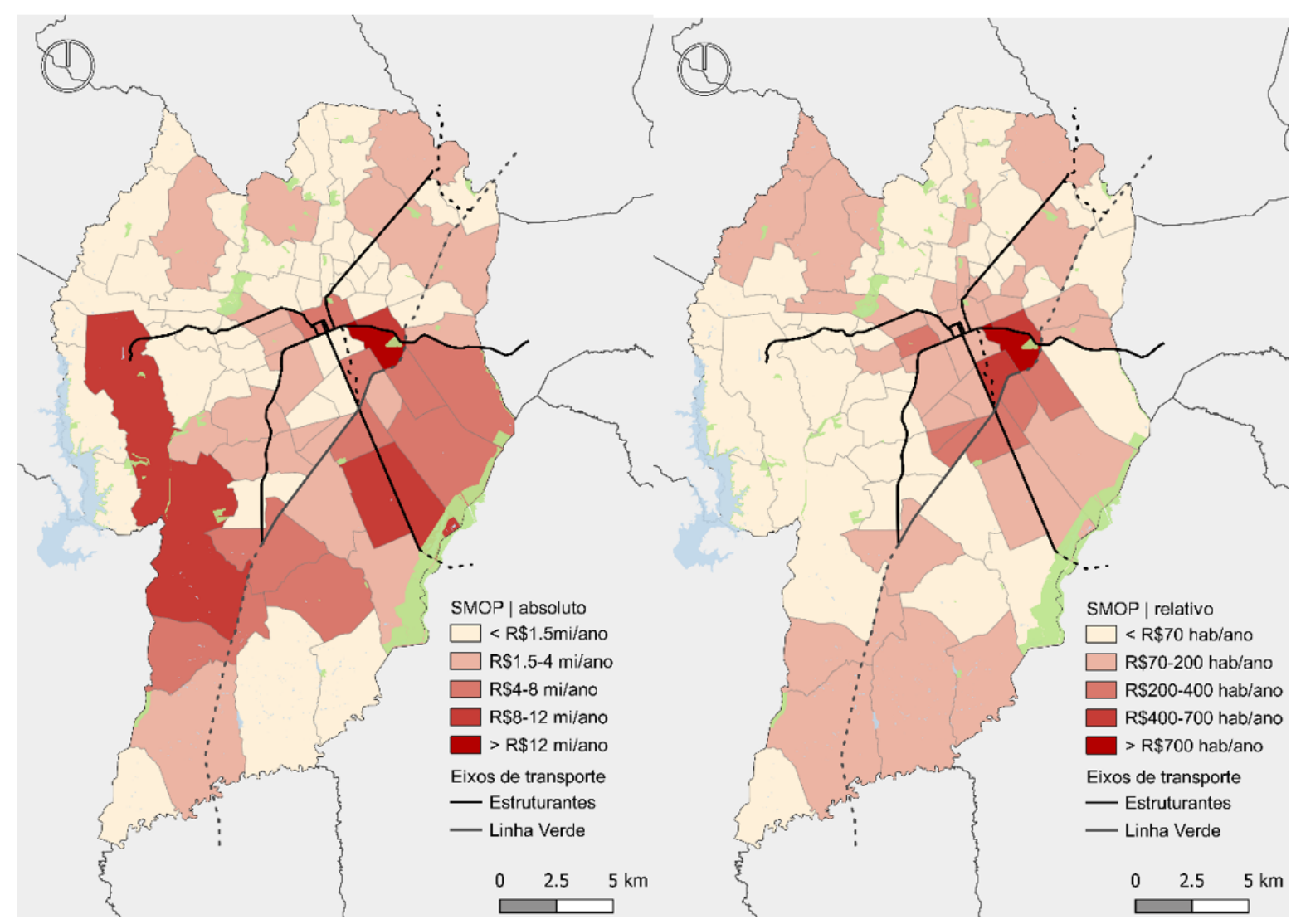

Figura 3 - Total aplicado em obras públicas por bairro de Curitiba, entre 2005 e 2016, em valores absolutos (à esquerda) e relativos (à direita). Fonte: Autores (2019), com dados da SMOP (Curitiba, 2016a).

A região central (Centro, Cristo Rei, Batel e Água Verde) está frequentemente na agenda de novos investimentos e recebe muitas intervenções de custos moderados. Porém, bairros periféricos, em especial na região sul de alta precariedade, também reúnem investimentos que, mesmo relativizados em termos unitários (valor investido por habitante), escapam dos eixos tradicionais de investimentos e que consolidaram as regiões mais nobres da cidade. Pinheirinho, Cidade Industrial, Boqueirão e Uberaba são exemplos nesse sentido.

Inclusive, nos primeiros anos de análise (PSDB), os recursos foram mais distribuídos espacialmente, priorizando regiões periféricas. Isso se relaciona com o perfil das obras realizadas: sobressaem-se as obras de edificações, como a construção de escolas, postos de saúde e de atendimento geral à população, que tendem a ser mais descentralizadas e com custo de construção relativamente menor do que seu custo de manutenção.

A partir de 2012 (PSB), e mais ainda em 2014 (PDT), verifica-se a influência das obras direcionadas à Copa do Mundo. Os recursos federais obtidos por meio do Programa de Aceleração do Crescimento (PAC) foram em grande parte concentrados em áreas nobres e na ligação do aeroporto com o centro da cidade. E, considerando o alto volume de recursos provenientes do programa, que se sobressai da capacidade municipal, tal configuração tem um efeito bastante expressivo na matriz de investimentos.

Ainda, seguindo os padrões encontrados em estudos recentes (Gonçalves et al., 2017), os últimos anos de gestão pública municipal têm se caracterizado por investimentos maiores e, no caso de Curitiba, em áreas nobres, conforme mostrado na Figura 4. Pode-se perceber picos em 2008, 2009, 
2012 e depois em 2014, que coincidem com os anos eleitorais e, no caso de 2014, com o ano da Copa do Mundo de Futebol ${ }^{4}$.

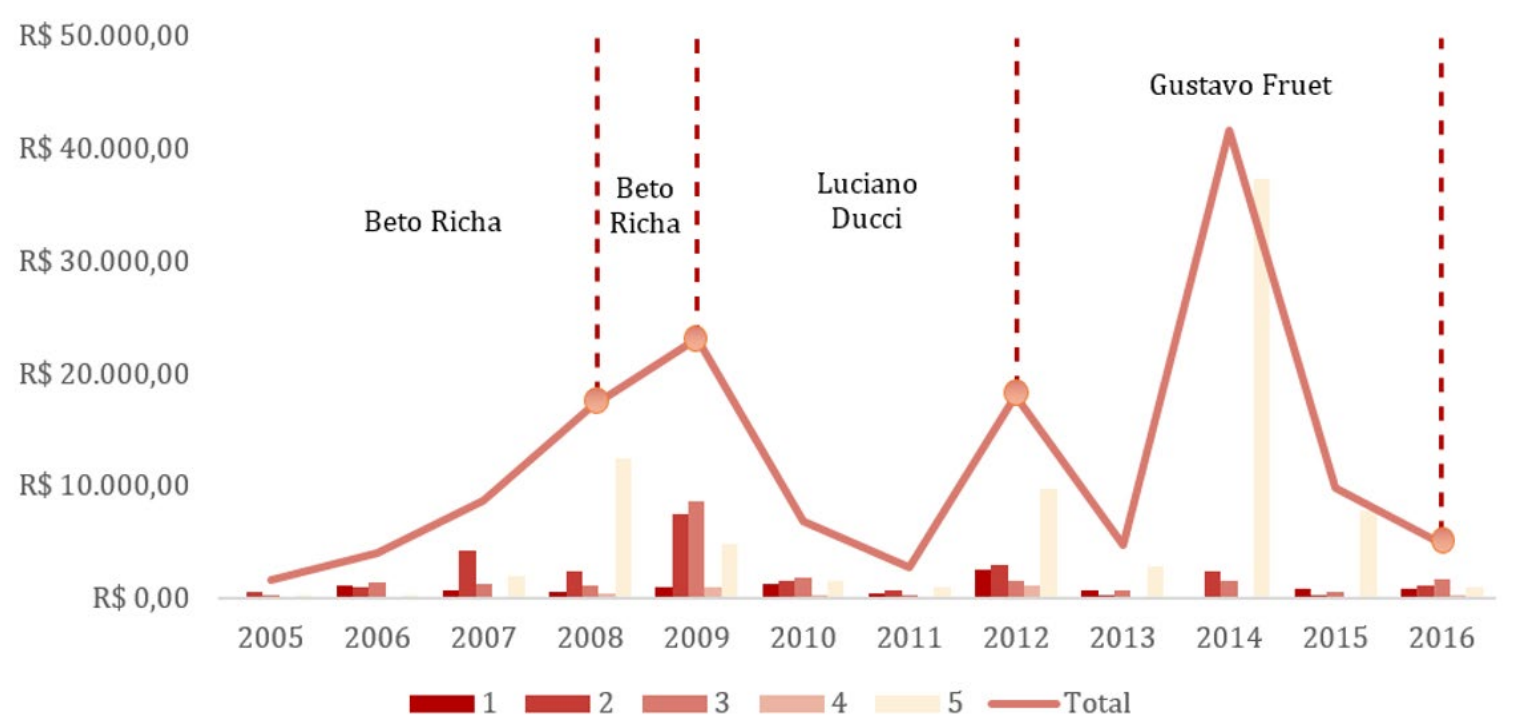

Figura 4 - Evolução dos recursos aplicados pela SMOP (R\$/hab.ano), entre 2005 e 2016, por gestão municipal. Fonte: Autores (2019), com dados da SMOP (Curitiba, 2016a).

Se de 2005 a 2007 bairros precários (1, 2 e 3) foram priorizados na alocação de investimentos em infraestrutura; em 2008, 80\% dos recursos foram aplicados nos bairros dos grupos 4 e 5.0 mesmo fenômeno é observado de 2009 a 2012, com este último ano destinando 51\% dos investimentos aos bairros menos precários. Tal proporção se acentua nos anos seguintes, até o pico em 2014 (93\% em bairros nobres).

Resumidamente, os vinte e oito bairros com os mais altos níveis de renda e infraestrutura (29\% da população) concentraram $60 \%$ dos investimentos públicos. Na dimensão oposta, os trinta e dois bairros de mais alta precariedade ( $56 \%$ da população) receberam apenas $25 \%$ dos investimentos. As obras no Jardim Botânico correspondem a grande parte dessa matriz, evidenciado pela alta média do grupo 5, conforme mostrado pela Figura 5. Entretanto, mesmo na análise mediana, os bairros mais precários - e que necessitariam de maiores investimentos para se desenvolverem - receberam anualmente de $\mathrm{R} \$ 10$ a 20 reais por habitante a menos do que bairros menos precários.

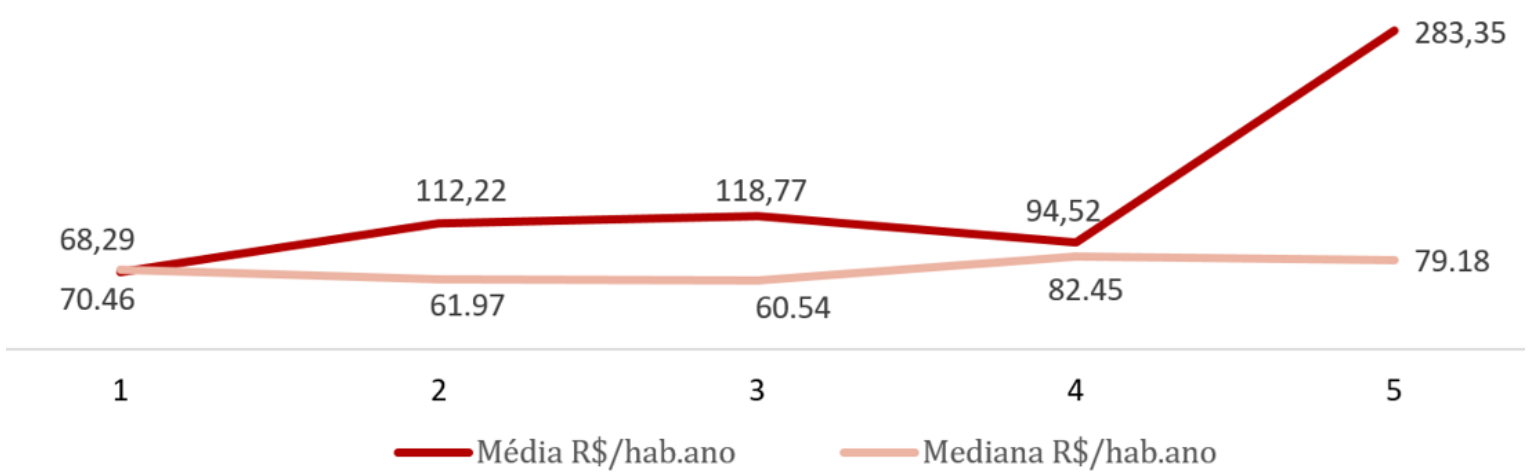

Figura 5 - Distribuição dos investimentos em obras públicas (R\$/hab.ano), segundo níveis de precariedade, entre 2005 e 2016. Fonte: Autores (2019), com dados da SMOP (Curitiba, 2016a).

\footnotetext{
4 O ano de 2009 marcou o último ano de Beto Richa como prefeito, haja vista sua renúncia a fim de concorrer ao governo do estado, servindo como vitrine eleitoral ao então futuro governador do Paraná.
} 
Além disso, na comparação entre os bairros mais precários de Curitiba, verifica-se que os investimentos são mais concentrados em periferias já consolidadas (Boqueirão, Cidade Industrial, Tatuquara e Prado Velho), em detrimento das áreas recentemente ocupadas (Riviera, Caximba e São Miguel). Isto é, as heterogeneidades presentes entre periferias somam-se às heterogeneidades dos investimentos, que não são suficientes para inverter o perfil histórico de priorização das regiões centrais e próximas aos eixos estruturantes, haja vista a melhor condição atual da infraestrutura nesses locais.

\section{Investimentos públicos e mercado imobiliário}

Segundo Maricato (2013b), a valorização das propriedades fundiárias seria o grande impulsor dos investimentos públicos, especialmente em obras de circulação viária. A simbiose entre infraestrutura e investimento imobiliário e a influência dos interesses privados nas gestões urbanas fariam com que a distribuição de recursos públicos fosse então mais orientada pela lógica de rentabilidade imobiliária e priorização do transporte individual motorizado, e menos pelo caráter social e coletivo da ação estatal. Para avaliar a abrangência desse fenômeno, parece produtivo analisar alguns elementos relativos ao comportamento do mercado imobiliário, tendo sempre como ponto de referência os investimentos públicos e as desigualdades socioespaciais.

Em primeiro lugar, seguindo a dinâmica de créditos e de construção em diversas cidades do mundo (Cerutti et al., 2017), a atividade imobiliária se intensificou em Curitiba entre 2005 e 2016, passando de 7 mil unidades habitacionais e comerciais construídas em 2005, ao pico de produção em 2010, com mais de 38 mil, e novamente em 2013, com 25 mil unidades. No Brasil, mas não somente, o alinhamento entre desregulação estatal, políticas massivas de infraestrutura e recursos financeiros provenientes da abertura de capitais na bolsa de valores provocou um aquecimento ímpar do setor de construção a partir dos anos 2000 (Lencioni, 2014; Castro \& Shimbo, 2010), que apenas veio a declinar com os efeitos tardios da crise imobiliária de 2008, que teve como epicentro o mercado norteamericano (Rolnik, 2015).

Em termos locacionais, os lançamentos concentraram-se em bairros nobres e de tradicional interesse do mercado imobiliário, mas também em periferias já consolidadas, conforme a Figura 6, ilustrando o movimento combinado de verticalização e expansão urbana (Lefebvre, 1979). Os grupos 4 e 5, centrais e de baixa precariedade, concentraram $41 \%$ das unidades lançadas entre 2005 e 2016 e em grande parte seguindo os eixos estruturantes que permitem maior verticalização segundo a legislação de zoneamento. Assim, apesar de o principal movimento construtivo ao longo dos eixos ter se concentrado nas décadas de 1990/2000 (Polucha, 2010), estes locais continuam a atrair novos empreendimentos, com preenchimento de vazios urbanos e reconstrução de edificações. Inclusive, vetores importantes de expansão imobiliária começam na região central e seguem o eixo nordeste-sudeste (Pinheirinho - Santa Cândida), estendendo-se para regiões periféricas consolidadas e que, a partir de 2010, passaram a se destacar na matriz de investimentos (Figura 3). 0 grupo 2, que congrega a maior parte desses bairros, recebeu $35 \%$ dos lançamentos imobiliários no período.

Fora do mercado formal de moradias, entretanto, os bairros mais precários do grupo 1 receberam apenas $11 \%$ das unidades novas, e com altas discrepâncias internas. Enquanto na zona sul o crescimento foi estimulado pela construção de um grande complexo da Companhia de Habitação Popular (Cohab), o que está associada aos investimentos em infraestrutura, na zona oeste foram menos de 20 unidades habitacionais ou comerciais regularizadas na SMU nos doze anos de análise. Tal fenômeno evidencia o processo de autoconstrução da casa e, dada a falta de recursos públicos em infraestrutura nestas regiões, também da cidade (Maricato, 1979). 


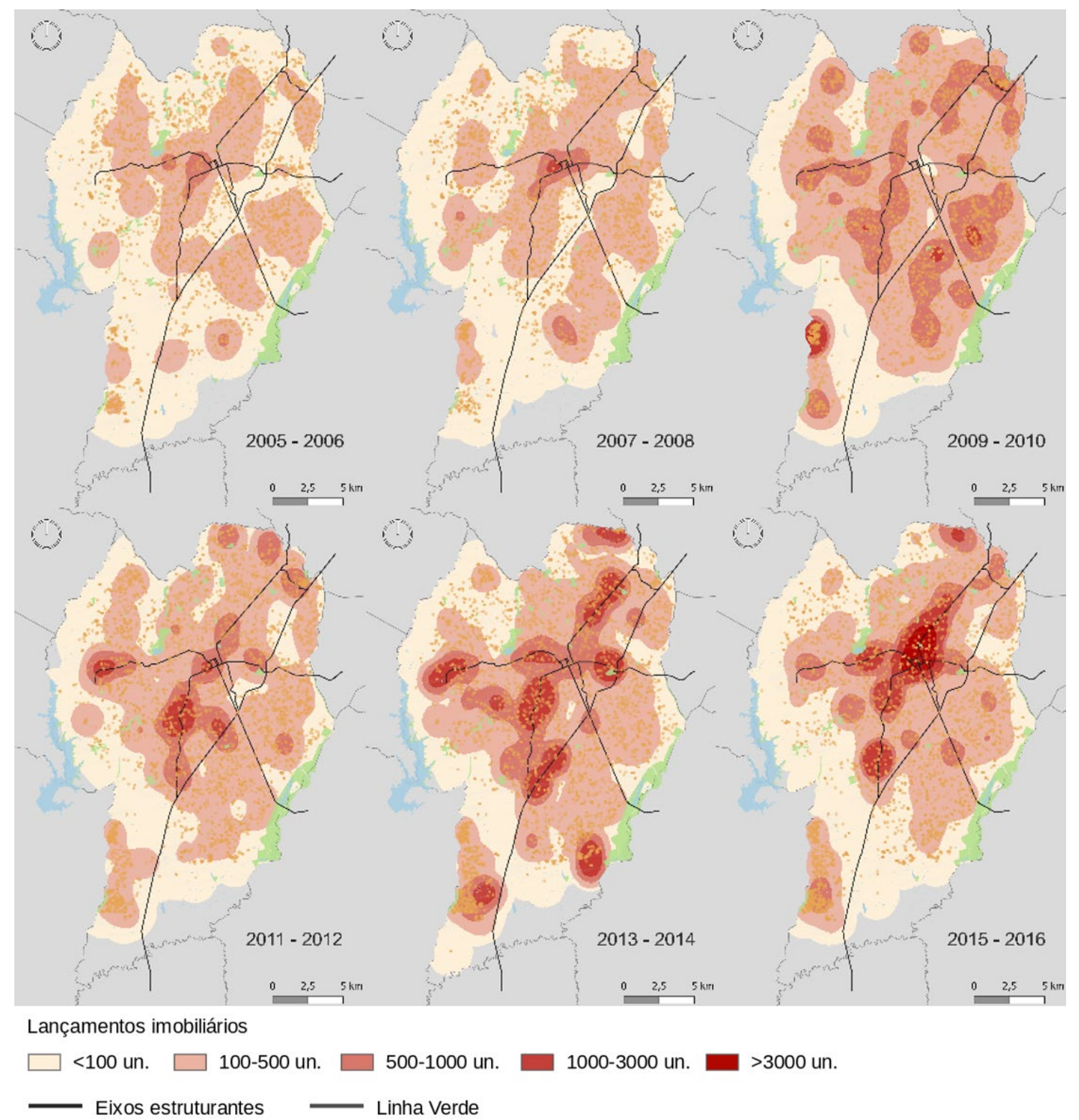

Figura 6 - Lançamentos imobiliários residenciais e comerciais entre 2005 e 2016. Fonte: Autores (2019), com dados da SMU (Curitiba, 2016b).

Em segundo lugar, a expansão da atividade imobiliária também é indicada pela valorização da terra urbana. Conforme a Figura 7, os imóveis novos em Curitiba são mais caros na região central, onde a condição da infraestrutura é melhor e o valor da terra urbana é mais alto. Contudo, além de uma aproximação dos preços dos lançamentos entre os bairros dos grupos 4 e 5 de baixa precariedade, centrais e ao longo dos eixos estruturais, verifica-se também a superação do centro por outros bairros de caráter predominantemente residencial. Se em 2006 o Centro e o Centro Cívico receberam os imóveis com os custos unitários mais altos de Curitiba - valores cerca de $20 \%$ mais altos do que o seu entorno -, em 2016 observa-se uma inversão desse fenômeno. Isto é, o entorno é agora mais caro e cada vez mais explorado pelo mercado imobiliário.

Isto mostra o aquecimento do mercado imobiliário residencial de alto padrão em bairros um pouco mais afastados, mas ainda bem localizados e com boa infraestrutura e acessibilidade. Estes condomínios, em sua maioria construídos por incorporadoras de abrangência nacional, apostam nos diferenciais de itens e espaços de lazer vinculados à ideia de comodidade, segurança e redução de deslocamentos, criando um imaginário de seletividade (Polucha, 2010). 


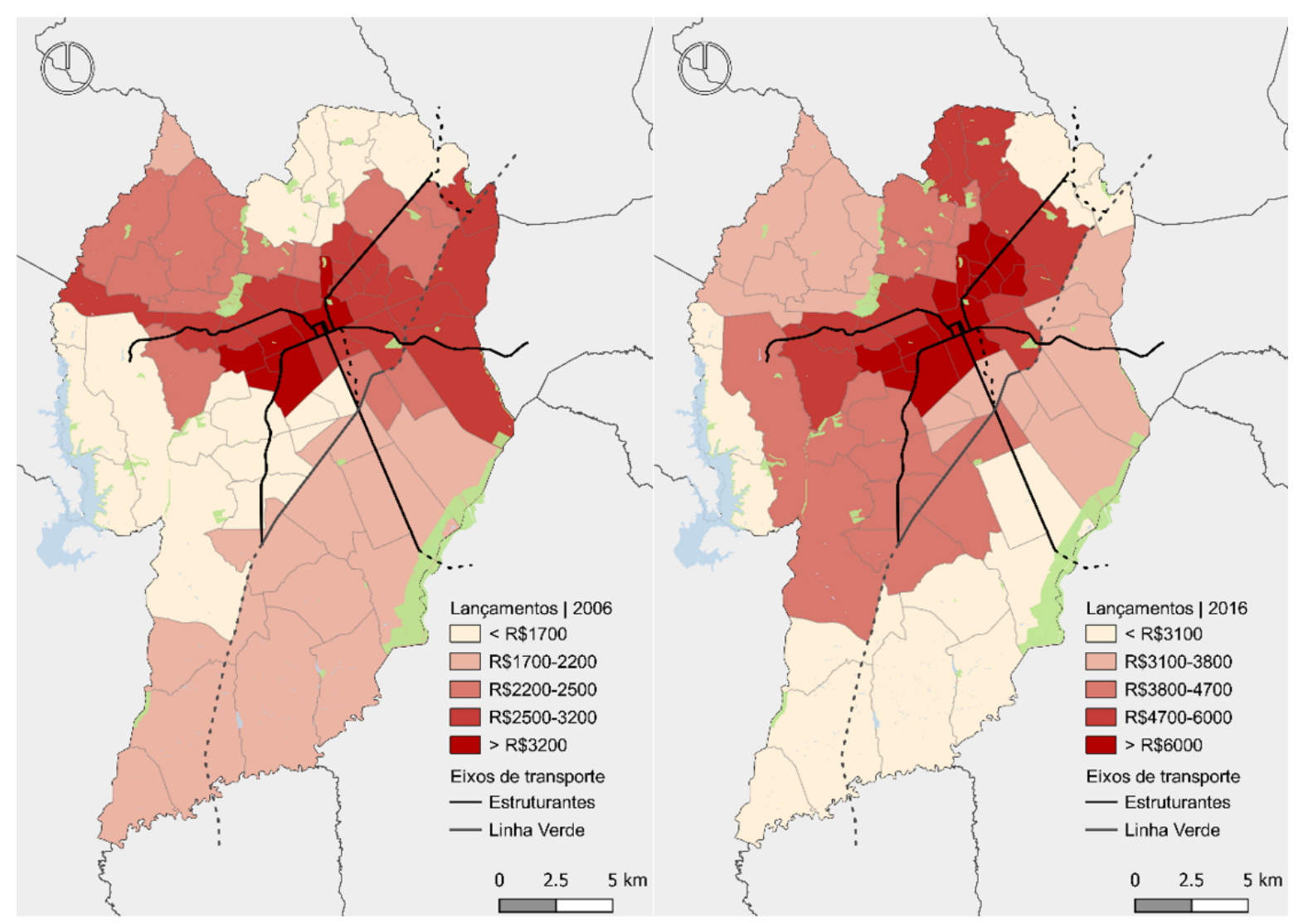

Figura 7 - Valores por $\mathrm{m}^{2}$ de área total dos lançamentos imobiliários em Curitiba, em 2006 e 2016. Fonte: Autores (2019), com dados do SINDUSCON $(2006,2016)$.

Além disso, de modo a superar a falta de terrenos vazios disponíveis e também do preço mais alto do solo nas áreas centrais, obtendo-se o aproveitamento máximo do solo urbano, constata-se uma tendência à compactação pela crescente verticalização e pelo aumento gradativo das unidades de apartamento em relação ao número de casas. Esta verticalização, embora tenha seguido razoavelmente as orientações das legislações urbanísticas, que determinam ocupações linearizadas ao longo dos eixos de transporte público coletivo de alta capacidade, provocou a alta valorização imobiliária destas zonas, conforme indicado na Figura 7, deixando às camadas populares a ocupação de áreas periféricas horizontalizadas, porém altamente adensadas.

Além do mais, se houve uma aproximação dos valores dos imóveis lançados nas regiões mais próximas ao centro, a desigualdade entre centro e periferia aumentou consideravelmente. Em 2006, o preço do $\mathrm{m}^{2}$ dos imóveis novos no Centro era um pouco mais do que o dobro do que nos bairros periféricos. Essa diferença aumentou para quase 3,5 vezes em 2016. Isto é, a ocupação da região central tornou-se mais seletiva, constituindo espaços de rendas mais homogêneas e elevadas.

Em terceiro lugar, o encarecimento dos imóveis novos está correlacionado à elevação do preço da terra urbana. Como mostrado na Figura 8, houve um aumento percentual maior do preço dos terrenos em bairros periféricos, constatando um aumento generalizado do custo de moradia em Curitiba e que contribui progressivamente para o processo de periferização e ocupação dos municípios da região metropolitana. Já em termos absolutos, a região central encareceu mais, mesmo que de maneira menos expressiva, do que a valorização dos lançamentos imobiliários.

Bairros tradicionais, com boa e regularmente revitalizada infraestrutura (Centro, Água Verde, Batel, Cristo Rei e Cabral), sobressaem-se dos demais, com valorizações superiores a $\mathrm{R} \$ 150 / \mathrm{m}^{2}$.ano. Aliás, esse próprio fato comprova a priorização de empreendimentos de luxo em localizações privilegiadas e destinadas à população de alta renda (Fernandes \& Firkowski, 2014), que acentuam ainda mais as desigualdades de acesso à habitação. 


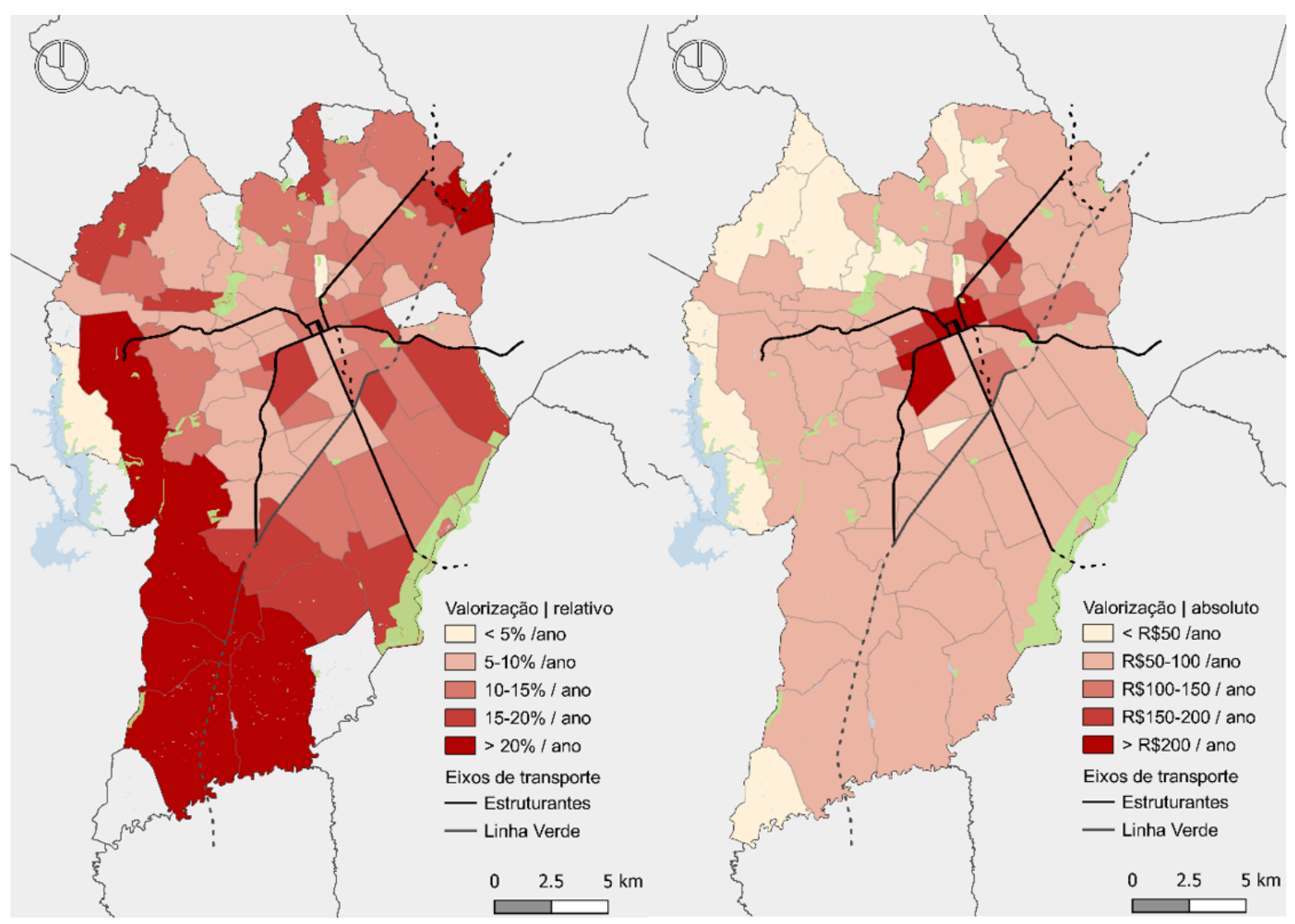

Figura 8 - Aumento do preço da terra urbana por m²/ano entre 2008 e 2016, em termos relativos (à esquerda) e absolutos (à direita). Fonte: Autores (2019), com dados do INPESPAR $(2008,2016)^{5}$.

Outro fenômeno interessante é a valorização pontual de bairros da região leste, afetados pela obra da Linha Verde e que receberam altos volumes de recursos em infraestrutura. A obra viária, em curso desde 2007, aliada às mudanças no zoneamento e nos parâmetros de uso e ocupação do solo, movimentaram o mercado imobiliário local, provocando aumentos expressivos no preço da terra urbana. Porém, essa valorização se deu primordialmente nos bairros mais próximos ao centro. Inclusive, ressalta-se que o processo especulativo e o interesse imobiliário na região não se converteram em contrapartidas satisfatórias ao poder público. Mesmo os mecanismos de venda dos Certificados de Potencial Adicional de Construção (CEPAC) vinculados à Operação Urbana Consorciada da Linha Verde (OUC-LV), que financiaram parte da obra, não atenderam às expectativas da prefeitura. Desde o início da OUC-LV até 2016, foram realizados cinco leilões com arrecadação total correspondente a pouco mais de $10 \%$ do valor aplicado na obra até então.

Destarte, a partir das análises apresentadas, verifica-se que grande parte das intervenções da prefeitura em obras públicas foram realizadas em localidades com boas condições de infraestrutura e em regiões - que já eram ou se tornaram - de particular interesse ao mercado imobiliário. Essa relação, entretanto, é complexa e não linear, temporal e espacialmente. Na correlação espacial destas variáveis, mostrada na Figura 9, verifica-se a concentração de um grande conglomerado de bairros precários com baixos investimentos públicos na região sudoeste, em oposição aos bairros tradicionais próximos à região central, de baixa precariedade e grandes volumes de obras.

${ }^{5}$ Foram usados dados de 2008 para análise do preço da terra urbana, devido à indisponibilidade de dados para um número considerável de bairros de Curitiba nos anos de 2006 e 2007. 


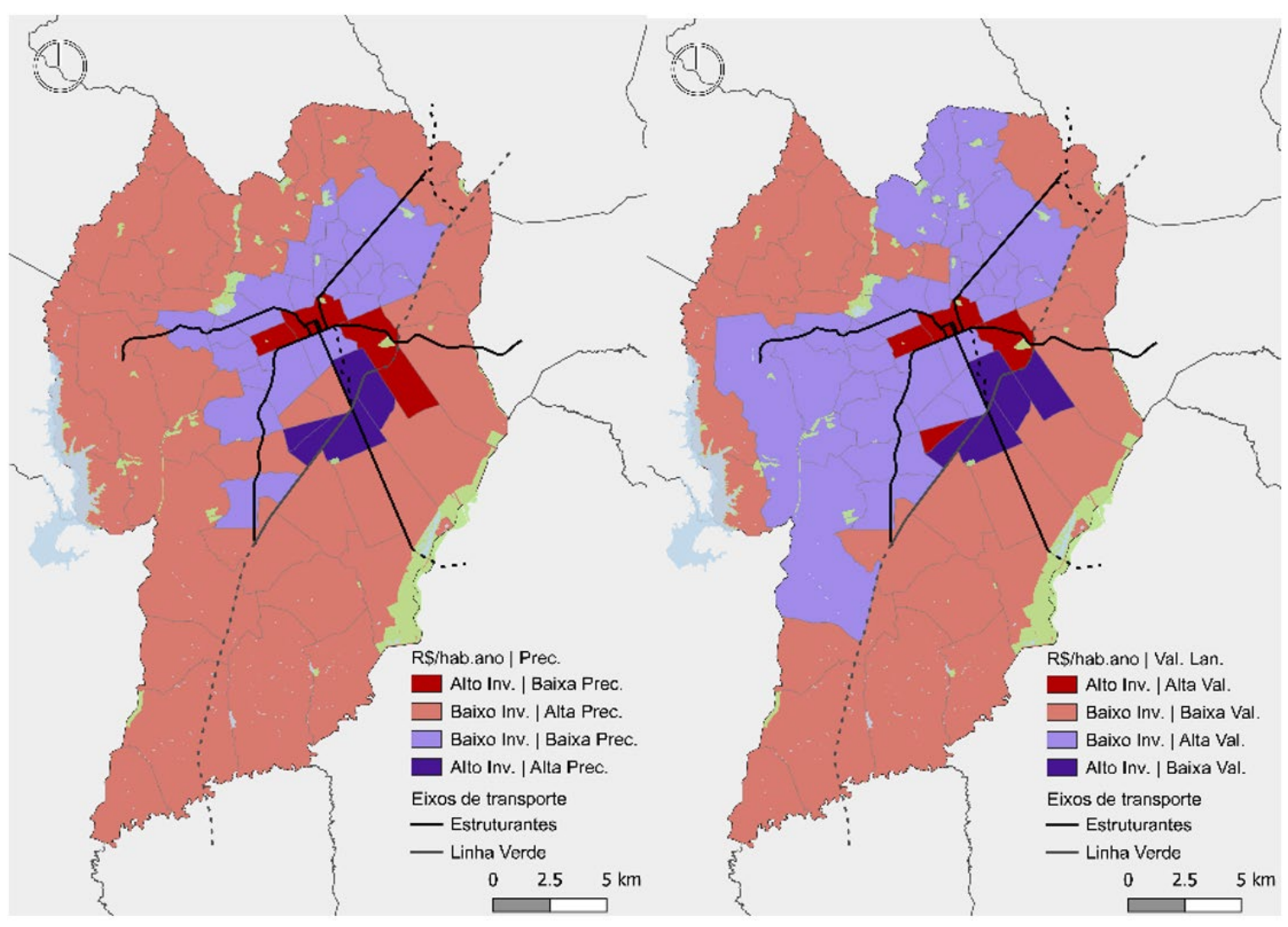

Figura 9 - Mapas bivariados entre investimentos públicos (R\$/hab.ano) entre 2005 e 2016 e nível de precariedade (à esquerda), e aumento do preço dos lançamentos imobiliários (à direita). Fonte: Autores (2019).

Verifica-se também que a localização das obras de infraestrutura tem efeitos diferenciais nos incrementos dos preços dos lotes. 0 aumento do preço por metro quadrado de um terreno situado dentro do anel central da cidade em função da intervenção pública urbana é maior do que o aumento para os lotes localizados no anel exterior da cidade. Tais diferenças acentuam-se a partir da combinação dos serviços disponíveis e da valorização dos lotes que quase sempre supera o custo do investimento para a provisão do serviço (Smolka, 2014).

\section{Conclusões}

A análise dos investimentos recentes em infraestrutura realizados em Curitiba oferece algumas contribuições para o debate sobre intervenção pública, ação privada e desigualdades históricas urbanas.

Primeiro, grandes obras com financiamento nacional, e especificamente no caso do PAC, importante em diversas cidades brasileiras na última década, superam a capacidade local de investimentos e se impõem na matriz de distribuição territorial. Poucas vezes se investiu tanto em infraestrutura urbana e de forma tão concentrada em tão pouco tempo como em meados dos anos 2010. Isso se manifesta em diferentes ordens em cidades com maior grau de inserção nos circuitos globais, como São Paulo e Rio de Janeiro (Sanchez et al., 2014), mas também em cidades menores como Belo Horizonte (Oliveira et al., 2012) e Curitiba, e se relaciona com a realização de megaeventos (corredor aeroportorodoferroviária), projetos de grande porte (Linha Verde) e construção de obras de arquitetura associadas a simbolismos urbanos (viaduto estaiado).

Segundo, evidenciando a relação entre eleições e investimentos públicos (Gonçalves et al., 2017), o calendário eleitoral impacta substantivamente a destinação de recursos em infraestrutura urbana. 
Porém, ao contrário do que indica a literatura sobre nexo eleitoral (Ames, 1995), verificou-se no caso em análise que investimentos são mais concentrados em áreas centrais, com boas condições urbanas e visibilidade no nível municipal. Isso indica que a mobilização política dos investimentos, ao menos em Curitiba, ocorre mais pela alta visibilidade das intervenções do que pela mobilização local de bases eleitorais periféricas. Se relações personalistas ou de vínculo eleitoral às bases territoriais mobilizam ações públicas pré-eleitorais (Rolnik, 1997; Kuschnir, 2000), se observa que os montantes aplicados na escala local não provocam impactos importantes na matriz de investimentos em infraestrutura.

Terceiro, o perfil político-eleitoral do executivo municipal importou pouco na distribuição de investimentos, como indicam estudos anteriores (Marques \& Bichir, 2001). Pode-se sugerir que isso ocorre: (i) pelo perfil político histórico de Curitiba que, mesmo em governos de oposição, apresenta uma certa continuidade de visões políticas e urbanas na cidade, com pouca abertura à participação popular e que não invertem o modo de planejar e intervir na cidade; e (ii) pelo contexto políticoeconômico recente, com grande volume de recursos orçamentários já comprometidos e definidos em uma conjunção de estratégias nacionais e locais, materializadas no PAC e relacionadas à realização de megaeventos.

Quarto, existe um movimento combinado de verticalização e expansão urbana que se reflete nos lançamentos residenciais e comerciais, mas não necessariamente na valorização e competição imobiliária. Apesar do avanço em direção às periferias consolidadas na cidade (Lefebvre, 1979), investimentos e retornos privados urbanos ainda se concentram em áreas centrais e que recebem continuamente intervenções públicas em infraestrutura. Isso indica um mercado imobiliário ainda não saturado e com espaço para expansão em regiões bem localizadas, cuja valorização por investimentos públicos e privados continua a se desenvolver.

Quinto, a relação entre investimentos públicos e investimentos imobiliários, contudo, não é automática, contribuindo com estudos que refutam teorias de captura do Estado por agentes privados (Sapotichne et al., 2007). Áreas que se beneficiaram de investimentos massivos em infraestrutura e que estão na agenda de projetos municipais há anos ainda não constituem focos importantes de atenção do mercado. Isso pode estar relacionado a um atraso na maturação na atuação imobiliária ou à disponibilidade de terras para desenvolvimento imobiliário em áreas mais interessantes e consolidadas, ainda não saturadas. De qualquer forma, os conflitos no espaço urbano e nas instituições de Estado constituem relações não lineares entre investimentos públicos e privados, apesar de as relações de poder existentes reafirmarem a distribuição desigual de recursos e a posição superior de determinados grupos e lugares.

Sexto, obras realizadas em áreas precárias da cidade tendem a ser projetos de edificações que, apesar de essenciais, não atuam na redução da vulnerabilidade quanto à infraestrutura e à qualidade dos deslocamentos e movimentos urbanos. Isto é, se existe uma forte aderência entre baixa oferta de serviços públicos, de saúde e educação, por exemplo, e maiores investimentos em equipamentos urbanos, ela não é igualmente verificada nos outros três aspectos analisados, pavimentação, iluminação e drenagem urbana, perpetuando as condições de desigualdade territorial. Essa desigualdade na descentralização espacial dos investimentos em equipamentos urbanos ou em obras viárias é comum às cidades brasileiras e está relacionada à próprias características dos empreendimentos. Os custos de edificação de escolas ou postos de saúde, executados pelo poder público municipal, são em geral menos variáveis, enquanto a mobilização financeira de obras de pavimentação, que concentram a maioria dos recursos municipais, tendem a variar significativamente de acordo com o projeto. Isto é, os grandes projetos de pontes, viadutos e readequação viária dos grandes centros contrastam com os recapeamentos ou asfaltamento das vias periféricas, refletindo na distribuição de investimentos.

Na dimensão local, independentemente do discurso do planejamento urbano de Curitiba sobre a qualidade urbana da cidade, o processo de desigualdade socioespacial, caracterizado pela repartição diferencial do solo, dos serviços e da infraestrutura urbanos segundo classes e grupos sociais, afirma a heterogeneidade da estrutura intraurbana da cidade e manifesta-se acentuadamente na periferia. Os 
recursos recentes aplicados em infraestrutura reforçam as políticas seletivas históricas do urbanismo curitibano e, apesar de existentes, não são suficientes para inverter ou aproximar substantivamente as condições desiguais de acesso entre centros e periferias, em seus sentidos mais amplos.

Observa-se então que aparente ausência do poder público em determinadas áreas da cidade, no que se refere à falta de políticas e investimentos públicos, representa também uma ação de Estado. Sendo um importante agente da organização territorial e responsável pela administração e distribuição de infraestruturas, bens e serviços urbanos, o poder público, ao estabelecer prioridades e opções de intervenção, incide tanto na produção de vantagens locacionais e valorização de imóveis, quanto na manutenção ou aprofundamento das precariedades relativas que reforçam a dinâmica de desigualdade.

\section{Referências}

Albuquerque, A. (2007). A questão habitacional em Curitiba: o enigma da "cidade-modelo" (Dissertação de mestrado). Faculdade de Arquitetura e Urbanismo, Universidade de São Paulo, São Paulo.

Ames, B. (1995). Electoral strategy under open-list proportional representation. American Journal of Political Science, 39(2), 406-433. http://dx.doi.org/10.2307/2111619.

Bertol, L. (2013). Terra e habitação: o problema e o falso problema (Dissertação de mestrado). Faculdade de Arquitetura e Urbanismo, Universidade de São Paulo, São Paulo.

Bittencourt, T. (2019). Planejamento urbano modelo e constituição das desigualdades socioespaciais: a infraestrutura do espaço intra-urbano de Curitiba. In Anais do XVIII ENANPUR (pp. 1-20). Natal: ANPUR.

Bonduki, N., \& Rolnik, R. (1979). Periferia da Grande São Paulo: reprodução do espaço como expediente de reprodução da força de trabalho. In E. Maricato (Ed.), A produção capitalista da casa (e da cidade) do Brasil industrial. São Paulo: Alfa-ômega.

Borges, L. M. M. (2009). Uma reflexão sobre a política urbana recente de Curitiba, entre 2001 e 2008, à luz do Estatuto da Cidade (Dissertação de mestrado). Programa de Pós-graduação em Desenvolvimento Econômico, Universidade Estadual de Campinas, Campinas.

Caldeira, T. (2000). Cidade de muros: crime, segregação e cidadania em São Paulo. São Paulo: Editora 34/Edusp.

Castells, M. (2009). A questão urbana. São Paulo: Paz e Terra.

Castro, C., \& Shimbo, L. (2010). Das cooperativas autofinanciadas às construtoras e incorporadoras de capital aberto: a ampliação do mercado habitacional. Revista Brasileira de Estudos Urbanos e Regionais, 12(2), 53-74. http://dx.doi.org/10.22296/2317-1529.2010v12n2p53.

Cerutti, C., Dagher, J., \& Dell'Ariccia, G. (2017). Housing finance and real-estate booms: a cross-country perspective. Journal of Housing Economics, 38, 1-13. http://dx.doi.org/10.1016/j.jhe.2017.02.001.

Cohen, M. (2020). The evolution of urban policy in developing countries. In: Cohen, M., Carrizosa, M., \& Gutman, M., eds Urban Policy in Latin America: Towards the Sustainable Development Goals? London, New York: Routledge.

Corrêa, R. (2014). Sobre agentes sociais, escala e produção do espaço: um texto para discussão. In A. Carlos, M. Souza, \& M. Sposito (Eds.), A produção do espaço urbano: agentes e processos, escalas e desafios (3. reimp.). São Paulo: Contexto.

Curitiba. Secretaria Municipal de Obras Públicas de Curitiba - SMOP. (2016a). Relatórios mensais de obras executadas ou contratadas entre 2005 e 2016. Curitiba.

Curitiba. Secretaria Municipal de Urbanismo de Curitiba - SMU. (2016b). Relatórios mensais dos Certificados de Vistoria de Conclusão de Obra (CVCO) entre 2005 e 2016. Curitiba. 
Chatterjee, S., \& Turnovsky, S. J. (2012). Infrastructure and inequality. European Economic Review, 56(8), 17301745. http://dx.doi.org/10.1016/j.euroecorev.2012.08.003.

Fernandes, F., \& Firkowski, O. (2014). Verticalização e novos produtos imobiliários de Curitiba. In O. Firkowski, \& R. Moura (Eds.), Curitiba: transformações na ordem urbana (pp. 278-304.). Rio de Janeiro: Letra Capital.

Firkowski, O., \& Moura, R. (2014). Curitiba: transformações na ordem urbana. Rio de Janeiro: Letra Capital.

Fix, M. (2007). São Paulo cidade global: fundamentos financeiros de uma miragem. São Paulo: Boitempo.

Furtado, C. (1944). A feição funcional da democracia moderna. Cultural Politics, 36(IV), 55-58.

Garcia, F. (1997). Cidade espetáculo: política, planejamento e city marketing. Curitiba: Palavra.

Gonçalves, L., Funchal, B., \& Bezerra Filho, J. (2017). A influência dos ciclos políticos nos investimentos públicos em infraestrutura: um estudo nos estados brasileiros no período de 2003 a 2014. Revista de Administração Pública, 51(4), 462-481. http://dx.doi.org/10.1590/0034-7612156337.

Hall, P., \& Taylor, R. (1996). Political Science and the three New Institutionalisms. Political Studies, 44(5), 936957. http://dx.doi.org/10.1111/j.1467-9248.1996.tb00343.x.

Harvey, D. (2006). A produção capitalista do espaço (2. ed.). São Paulo: Anablume.

Harvey, D. (2014). Cidades rebeldes. São Paulo: Martins Fontes.

Instituto Brasileiro de Geografia e Estatística - IBGE. (2010). Censo demográfico de 2010. Rio de Janeiro.

Instituto Paranaense de Pesquisa e Desenvolvimento do Mercado e Condominial - INPESPAR. (2008). Preço médio dos terrenos e imóveis residenciais e comerciais usados, ofertados para a venda na cidade de Curitiba em 2008. Curitiba.

Instituto Paranaense de Pesquisa e Desenvolvimento do Mercado e Condominial - INPESPAR. (2016). Preço médio dos terrenos e imóveis residenciais e comerciais usados, ofertados para a venda na cidade de Curitiba em 2016. Curitiba.

Jessop, B. (2016). The state: past, present, future. Cambridge: Polity Press.

Jordan, R., \& Livert, F. (2016). Um velho desafio e um novo problema: planejamento da infraestrutura na América Latina. In R. Balbim (Ed.), Geopolítica das cidades: velhos desafios, novos problemas. Brasília: Ipea.

Karabarbounis, L. (2011). One dollar, one vote. Economic Journal, 121(553), 621-651.

http://dx.doi.org/10.1111/j.1468-0297.2010.02406.x.

Kowarick, L. (1979). A espoliação urbana. São Paulo: Paz e Terra.

Kowarick, L. (2000). Escritos urbanos. São Paulo: Editora 34.

Kuschnir, K. (2000). O cotidiano da política. Rio de Janeiro: Zahar.

Lefebvre, H. (2011). O direito à cidade. São Paulo: Centauro.

Lefebvre, R. (1979). Notas sobre o papel dos preços de terrenos em negócios imobiliários de apartamentos e escritórios na cidade de São Paulo. In E. Maricato (Ed.), A produção capitalista da casa (e da cidade) no Brasil industrial. São Paulo: Alfa-Ômega.

Lencioni, S. (2014). Reestruturação imobiliária: uma análise dos processos de concentração e centralização do capital no setor imobiliário. EURE. Revista Latinoamericana de Estudios Urbano Regionales, 40(120), 29-47. http://dx.doi.org/10.4067/S0250-71612014000200002.

Lojkine, J. (1997). O estado capitalista e a questão urbana. São Paulo: Martins Fontes.

Mahdi, S., Massarongo, F., \& Massingue, A. (2019). Desigualdades espaciais no acesso à infraestruturas básicas em Moçambique. Washington, D.C.: World Bank Group. 
Maloutas, T. (2008). Residential segregation in context. In T. Maloutas, \& K. Fujita (Eds.), Residential segregation in comparative perspective (pp. 1-342.). London: Ashgate.

Maricato, E. (1979). A produção capitalista da casa (e da cidade) no Brasil industrial. São Paulo: Alpha-Ômega.

Maricato, E. (2013a). Brasil, cidades: alternativas para a crise urbana. Petrópolis: Vozes.

Maricato, E. (2013b). As ideias fora do lugar e o lugar fora das ideias. In O. Arantes, E. Maricato, \& C. Vainer, (Eds.), A cidade do pensamento único. Petrópolis: Vozes.

Marques, E. (2000). Estado e redes sociais: permeabilidade e coesão nas políticas urbanas no Rio de Janeiro. São Paulo: Revan/Fapesp.

Marques, E. (2016). Os capitais do urbano no Brasil. Novos Estudos CEBRAP, 35(2), 11-12.

http://dx.doi.org/10.25091/S0101-3300201600020001.

Marques, E., \& Bichir, R. (2001). Investimentos públicos, infra-estrutura urbana e produção da periferia em São Paulo. Revista Espaço e Debates, 42, 9-30.

Moura, R. (2009). Arranjos urbano-regionais no Brasil: uma análise com foco em Curitiba (Tese de doutorado). Programa de Pós-graduação em Geografia, Setor de Ciências da Terra, Universidade Federal do Paraná, Curitiba.

Oliveira, D. (2000). Curitiba e o mito da cidade modelo. Curitiba: UFPR.

Oliveira, F., Costa, H., Cardoso, A., \& Vainer, C. (2012). Grandes projetos metropolitanos: Rio de Janeiro e Belo Horizonte. Rio de Janeiro: Letra Capital.

Piketty, T. (2014). O capital no século XXI. Rio de Janeiro: Intrínseca.

Pilotto, A. (2010). Área metropolitana de Curitiba: um estudo a partir do espaço intra-urbano (Dissertação de mestrado). Faculdade de Arquitetura e Urbanismo da Universidade de São Paulo.

Pires, R. (2019). Implementando desigualdades: reprodução de desigualdades na implementação de políticas públicas. Rio de Janeiro: IPEA.

Polucha, R. (2010). Ecoville: construindo uma cidade para poucos (Dissertação de mestrado). Faculdade de Arquitetura e Urbanismo da Universidade de São Paulo.

Polli, S. (2006). Curitiba, Metrópole Corporativa: fronteiras da desigualdade (Dissertação de mestrado). Programa de Pós-graduação em Planejamento Urbano e Regional, Universidade Federal do Rio de Janeiro, Rio de Janeiro.

Poulantzas, N. (1980). O estado, o poder, o socialismo. Rio de Janeiro: Graal.

Povitkina, M., \& Bolkvadze, K. (2019). Fresh pipes with dirty water: how quality of government shapes the provision of public goods in democracies. European Consortium for Political Research, 58(4), 1191-1212. http://dx.doi.org/10.1111/1475-6765.12330.

Rolnik, R. (1997). A cidade e a lei: legislação, política urbana e territórios na cidade de São Paulo. São Paulo: Studio Nobel.

Rolnik, R. (2015). Guerra dos lugares. São Paulo: Boitempo.

Roy, A., \& Crane, E. (2015). Territories of poverty: rethinking north and south. Athens: University of Georgia Press, Geographies of Justice and Social Transformation series.

Sader, E. (1988). Quando novos personagens entraram em cena. Rio de Janeiro: Paz e Terra.

Sanchez, F., Bienenstein, G., Oliveira, F., \& Novais, P. (2014). A Copa do Mundo e as cidades: políticas, projetos e resistências. Niterói: EdUFF.

Santos, M. (2012). Por uma economia política da cidade. São Paulo: Edusp. 
Sapotichne, J., Jones, B., \& Wolfe, M. (2007). Is urban politics a black hole? Analyzing the boundary between political science and urban politics. Urban Affairs Review, 43(1), 76-106.

http://dx.doi.org/10.1177/1078087407302901.

Silva, M. N. (2012). A dinâmica da produção dos espaços informais de moradia e o processo de metropolização em Curitiba (Tese de doutorado). Pós-graduação em Geografia, Setor de Ciências da Terra, Universidade Federal do Paraná, Curitiba.

Sindicato das Indústrias da Construção Civil do Paraná - SINDUSCON. (2006). Pesquisa imobiliária de preços: dezembro de 2006. Curitiba.

Sindicato das Indústrias da Construção Civil do Paraná - SINDUSCON. (2016). Pesquisa imobiliária de preços: dezembro de 2016. Curitiba.

Singer, P. (2010). Economia política da urbanização (2. ed.). São Paulo: Contexto.

Smolka, M. (2014). Recuperação de Mais-Valias Fundiárias na América Latina. Cambridge: Lincoln Institute of Land Policy.

Souza, C. (2006). Políticas públicas: uma revisão da literatura. Revista Sociologias, (16), 20-45.

Souza, N. (2001). Planejamento urbano em Curitiba: saber técnico, classificação dos citadinos e partilha da cidade. Revista de Sociologia e Politica, 16(16), 107-122. http://dx.doi.org/10.1590/S010444782001000100008.

Steinberger, M. (2013). Território, Estado e políticas públicas espaciais. Brasília: Ler Editora.

Sugai, M. (2002). Segregação silenciosa: investimentos públicos e distribuição sócio-espacial na área conurbada de Florianópolis (Tese de doutorado). Faculdade de Arquitetura e Urbanismo, Universidade de São Paulo, São Paulo.

Torres, H., Marques, E., \& Bichir, R. (2006). Políticas públicas, pobreza urbana e segregação residencial. In J. M. P. Cunha (Ed.), Novas metrópoles paulistas: população, vulnerabilidade e segregação (pp. 231-252). Campinas: UNICAMP.

Urbanização Curitiba S.A. - URBS. (2017). Dados de operação do transporte público no formato General Transit Feed Specification (GTFS). Curitiba.

Vainer, C. (2012). Pátria, empresa e mercadoria: notas sobre a estratégia discursiva do Planejamento Estratégico Urbano. In O. Arantes, E. Maricato, \& C. Vainer (Eds.), A cidade do pensamento único. Petrópolis: Vozes.

Verbist, G., Förster, M., \& Vaalavuo, M. (2012). The impact of publicly provided services on the distribution of resources: review of new results and methods (OECD Working Papers, No. 130). Paris: OECD.

Vetter, D., Pinto, D., Fredrich, O., \& Massena, R. (1981). A apropriação dos benefícios das ações do Estado em áreas urbanas: seus determinantes e análise através de ecologia fatorial. Revista Brasileira de Geografia, 43(4), 457-476.

Villaça, F. (1998). O espaço intra-urbano no Brasil. São Paulo: Studio Nobel.

Editor: Paulo Nascimento Neto

Recebido: Out. 20, 2019

Aprovado: Set. 06, 2020 